\title{
Manejo da palhada e adubação na produção da soja e cobertura do solo
}

\author{
José Wilson CORTEZ ${ }^{*}$, Carlos Eduardo Angeli FURLANI², Rouverson Pereira da SILVA², \\ Salvio Napoleão Soares ARCOVERDE ${ }^{1}$
}

\author{
${ }^{1}$ Universidade Federal da Grande Dourados, Dourados, MS, Brasil \\ ${ }^{2}$ Universidade Estadual Paulista Júlio de Mesquita Filho, Jaboticabal, SP, Brasil \\ *E-mail: jorgewcortez@gmail.com
}

Recebido em setembro/2018; Aceito em abril/2019.

\begin{abstract}
RESUMO: Diversos fatores podem interferir no desenvolvimento da cultura da soja, dentre os quais pode-se citar o manejo de restos culturais e o método de aplicação do adubo. Assim, objetivou-se avaliar os equipamentos de manejo da palhada (rolo-faca, triturador de palhas e roçadora) e sistemas de adubação (em pré-semeadura e na semeadura), na produção da soja e cobertura do solo. O experimento foi conduzido em Latossolo Vermelho utilizando-se um esquema fatorial 2 x 3 em blocos casualizados com quatro repetições. Foram avaliados: estande inicial e final, distribuição longitudinal, altura de planta e inserção da primeira vagem, número de vagens por planta e número de grãos por vagem, massa de 100 grãos e produtividade além da porcentagem de cobertura do solo e biomassa seca no solo. Os sistemas de manejo da palhada, individualmente, influenciaram as variáveis: estande, altura de inserção da primeira vagem e número de vagens por planta. A interação manejo da palhada e adubação, seja na semeadura ou pré-semeadura, não influenciaram a produtividade da soja. A cobertura do solo foi maior para o tratamento com rolo-faca com adubação em pré-semeadura. A massa seca no solo foi maior após manejo para o triturador na adubação em pré-semeadura.
\end{abstract}

Palavras-chave: resíduos agrícolas; desenvolvimento de cultura; uniformidade de distribuição.

\section{Straw management and fertilization in soybean production and soil cover}

\begin{abstract}
Several factors can interfere in the development of the soybean crop, among which we can mention the management of cultural remains and the method of applying the fertilizer. The objective of this study was to evaluate straw management equipment (knife roller, rotary mower and straw crusher) and fertilization systems (before sowing and sowing), soybean production and soil cover. The experiment was conducted in Red Latosol using a 2 × 3 factorial randomized block design with four replicates. The initial and final stand, longitudinal distribution, plant height and insertion of the first pod, number of pods per plant and number of grains per pod, mass of 100 grains and yield in addition to the percentage of soil cover and dry biomass in the soil. The straw management systems, individually, influenced the variables: stand, height of insertion of the first pod and number of pods per plant. The interaction between straw management and fertilization, whether at sowing or before sowing, did not influence soybean yield. Soil cover was higher for the treatment with a knife roller with fertilization in pre-sowing. The dry mass in the soil was higher after handling to the straw crusher in the before seeding fertilization.
\end{abstract}

Keywords: agricultural wastes; growth stages; distribution uniformity.

\section{INTRODUÇÃO}

O cultivo da soja com elevado nível tecnológico tem encontrado dificuldades, principalmente na adoção de sistemas de cultivo que proporcionem a manutenção dos estoques de matéria orgânica no solo (KRUTZMANN et al., 2013; ORMOND, 2013). Assim, a busca por sistemas alternativos de produção devem basear-se no uso e manejo adequado do solo, que proporcionam condições favoráveis para a germinação de sementes, crescimento de raízes e também disponibilizar a água e os nutrientes necessários ao desenvolvimento das culturas, além de contribuir para o controle de pragas, doenças e plantas daninhas (TAVARES et al., 2012).

O tempo de adoção de sistemas conservacionistas como o plantio direto pode trazer efeitos positivos no solo, diminuindo a resistência à penetração e a densidade do solo nas propriedades com 15 e 11 anos, e em propriedades com menos anos de adoção do sistema deve ser feito monitoramento da compactação (DOMIT et al., 2014).

Ao contrário o sistema de preparo convencional pode promover acelerada degradação do solo, proporcionando desequilíbrio das propriedades físicas, químicas e biológicas do solo, e por consequência disto, alterações negativas no seu potencial produtivo (BEUTLER et al., 2014). Assim, o uso contínuo do sistema plantio direto proporciona efeitos significativos na melhoria da conservação do solo e da água; tendo como consequência o melhor aproveitamento dos recursos e insumos, como os fertilizantes, na redução de custos e estabilidade da produção (CHIODEROLI et al., 2012).

$\mathrm{O}$ uso de equipamentos que venham proporcionar condições ideais para a semeadura, normalmente tem rendimento operacional baixo, principalmente se utilizado a haste sulcadora (botinha). Entretanto, em relação aos efeitos da palhada sobre o desempenho da semeadura e também sobre 
o desenvolvimento de culturas ainda são poucas informações (TROGELLO et al., 2013).

Ações conservacionistas na agricultura atual, além de contribuir na melhoria das condições físico-químico-hídricas do solo, têm promovido mudanças na forma de adubação e de como fornecer os nutrientes as culturas. $\mathrm{O}$ uso da adubação antecipada na cultura da soja com adubos revestidos por polímeros pode proporcionar ganhos de produtividade (GUARESCHI et al., 2011) Para isto, a adubação vem sendo otimizada tanto na semeadura quanto na pré-semeadura por meio de adubos verdes, a fim de elevar a produtividade associada a práticas de manejo mais eficientes (SILVA; LAZARINI, 2014).

Portanto, objetivou-se avaliar os diferentes métodos de manejo da palhada (rolo-faca, triturador de palhas e roçadora) e sistemas de adubação (em pré-semeadura e na semeadura) nos componentes de produção da soja e cobertura do solo.

\section{MATERIAL E MÉTODOS}

$\mathrm{O}$ experimento foi conduzido na área experimental da UNESP/Jaboticabal, SP, localizada nas coordenadas geodésicas: latitude $21^{\circ} 14^{\prime} \mathrm{S}$ e longitude $48^{\circ} 16^{\prime} \mathrm{W}$, com altitude média de $559 \mathrm{~m}$, declividade média de $4 \%$, ocupando área de aproximadamente 1,0 ha. O clima, de acordo com a classificação de Köppen, é Aw, subtropical úmido, com estiagem no período do inverno.

$\mathrm{O}$ solo da área experimental foi classificado em Latossolo Vermelho Eutroférrico típico, A moderado, textura argilosa (55\%) e relevo suave ondulado (EMBRAPA, 2013). Realizouse amostragem de solo para determinação das análises química (Tabela 1), que serviram para a recomendação de adubação de semeadura (RAIJ et al., 1985).

As culturas utilizadas na safra de verão em sucessão foram soja e milho e no inverno as culturas utilizadas na rotação foram milheto, mucuna cinza, crotalária, sorgo, triticale e aveia, com posterior instalação deste experimento. Foi utilizado o delineamento em blocos ao acaso, em esquema fatorial $3 \times 2$, sendo três manejos dos restos culturais da safra anterior (rolagem por meio do rolo-faca, trituração por meio do triturador de palhas e roçada com a roçadora) e dois sistemas de adubação (em pré-semeadura e na semeadura) com quatro repetições. Cada parcela experimental ocupou área de $300 \mathrm{~m}^{2}(25 \times 12 \mathrm{~m}) \mathrm{e}$, entre as parcelas, no sentido longitudinal, foi reservado um espaço de $15 \mathrm{~m}$, destinado a realização de manobras, tráfego de máquinas e estabilização dos conjuntos mecanizados.

Inicialmente, foi utilizado o herbicida Glifosato $480 \mathrm{~g} \mathrm{~L}^{-1}$, com dose de $6 \mathrm{~L} \mathrm{ha}^{-1}$, para controlar plantas daninhas. $\mathrm{O}$ manejo foi realizado sobre restevas de milho do ano anterior e na presença das plantas daninhas, capim amargoso (Digitaria insularis) e nabiça (Raphanus raphanistrum L.), em toda a área, 30 dias antes da semeadura. Posteriormente utilizou-se para operação de manejo residual de cultura anual conjunto trator-equipamento nas velocidades médias: rolo-faca a 10,6 $\mathrm{km} \mathrm{h}^{-1}$, triturador a $9 \mathrm{~km} \mathrm{~h}^{-1}$ e roçadora a $8,8 \mathrm{~km} \mathrm{~h}^{-1} . \mathrm{Na}$ aplicação do adubo, em pré-semeadura, utilizou-se o conjuntotrator-distribuidor a lanço nas parcelas aos doze dias antes da semeadura, com velocidade média de $9,0-\mathrm{kmh}^{-1}$; enquanto que na semeadura utilizou-se semeadora-adubadora, com velocidade média do conjunto trator-semeadora-adubadora de $9,4 \mathrm{~km} \mathrm{~h}^{-1}$.

$\mathrm{Na}$ semeadura, o conjunto semeadora-adubadora estava com todos os mecanismos de contato com o solo (disco de corte, haste sulcadora para adubo, disco duplo para a semente, rodas de controle de profundidade e rodas compactadoras) com velocidade média de $7,8 \mathrm{~km} \mathrm{~h}^{-1}$.

A variedade de soja foi de ciclo precoce - Embrapa 48 (444.444,4 plantas por hectare), semeada a $4 \mathrm{~cm}$ de profundidade. As sementes foram tratadas com Fipronil na dose de $50 \mathrm{~g} \mathrm{ha}^{-1}$, e inoculante líquido Bradyrhizobium japonicum e elkanii na dose de 6.000 .000 células via líquida (50 L ha-1). O adubo utilizado para a adubação foi o fertilizante na fórmula 04-20-20 (NPK) na dose de $230 \mathrm{~kg} \mathrm{ha}^{-1}$ na adubação em pré-semeadura a lanço, e na semeadura depositado a profundidade de $11 \mathrm{~cm}$.

Tabela 1. Análise química do solo da área experimental.

Table 1. Soil chemical analysis of the experimental area.

\begin{tabular}{|c|c|c|c|c|c|c|c|c|c|c|}
\hline \multirow[t]{2}{*}{ Prof. } & $\mathrm{pH}$ & MO & $P$ & $\mathrm{~K}$ & $\mathrm{Ca}$ & $\mathrm{Mg}$ & $\mathrm{H}+\mathrm{Al}$ & SB & $\mathrm{T}$ & \multirow{2}{*}{$\frac{\mathrm{V}}{\%}$} \\
\hline & $\mathrm{CaCl}_{2}$ & $\mathrm{~g} \mathrm{dm}^{-3}$ & $\mathrm{mg} \mathrm{dm}^{-3}$ & \multicolumn{6}{|c|}{ - } & \\
\hline $0-10$ & 5,8 & 30 & 75 & 4,3 & 67 & 40 & 22 & 111 & 133 & 83 \\
\hline $10-20$ & 5,2 & 26 & 51 & 3,1 & 37 & 15 & 38 & 55 & 93 & 59 \\
\hline $20-40$ & 5,2 & 19 & 24 & 2,8 & 30 & 9 & 28 & 42 & 70 & 60 \\
\hline
\end{tabular}

MO: matéria orgânica; P: fósforo em resina; SB: soma de bases; T: capacidade de troca de cátions a pH 7,0. V: saturação por bases do solo.

Após a semeadura, e devido a infestação da Lagarta Elasmo (Elasmopalpus lignosellus) foi utilizado Cypermethrin na dose de $150 \mathrm{~mL} \mathrm{ha}^{-1}$. Aos 15 dias após a semeadura, foi utilizado Bentazon na dose $1,2 \mathrm{~L} \mathrm{ha}^{-1}$. Para controle da Ferrugem Asiática foi aplicado fungicida Epoxiconazole, sendo $500 \mathrm{~mL} \mathrm{ha}^{-1}$ e segunda aplicação com Azoxistrobina e Ciproconazole na dose de $300 \mathrm{~mL} \mathrm{ha}^{-1}$. Para o controle de percevejos verde e marrom foi utilizado Endosulfan, na dose de 1,5 $\mathrm{L} \mathrm{ha}^{-1}$. Com o aparecimento das doenças de final de ciclo (Mancha Parda - Septoriose glycines e Cercospora Cercospora kikuchii) fez-se aplicação de Tebuconazole na dose de $300 \mathrm{~mL} \mathrm{ha}^{-1}$ com $300 \mathrm{~L} \mathrm{ha}^{-1}$ de calda. Na Tabela 2 podem ser verificados os equipamentos agrícolas utilizados para execução dos tratamentos e aplicação dos insumos.

Foi determinada a porcentagem de cobertura do solo (palha e soja) antes e 30 dias depois da semeadura, utilizando-se um fio de cobre encapado com 7,5 m de comprimento e com marcações equidistantes $15 \mathrm{~cm}$, duas estacas nas pontas para fixação do fio rente ao solo, resultando em 50 pontos de leitura, sendo realizadas duas leituras nas diagonais da parcela, totalizando 100 pontos (Adaptado de LAFLEN et al., 1981).

Para determinação da massa seca no solo utilizou-se um quadrado de ferro de $0,25 \mathrm{~m}^{2}$, sendo lançado quatro vezes na área perfazendo $1 \mathrm{~m}^{2}$, avaliada aos $30,60,90 \mathrm{DAS}$, coletandose uma amostra por parcela, seca em estufa a $70{ }^{\circ} \mathrm{C}$ por 48 horas até atingir massa constante. As determinações foram realizadas na área antes do manejo mecanizado, após o manejo e após a semeadura.

$\mathrm{Na}$ determinação do estande inicial e final de plantas de soja, foi utilizado um sarrafo de madeira de comprimento igual a um metro. No campo, foi colocada esta ferramenta junto à fileira de plantas de soja e efetuou-se a contagem do número 
de plantas neste espaço correspondente ao comprimento do sarrafo. As contagens foram realizadas na fileira central de cada parcela tomando-se o cuidado de realizar as avaliações no mesmo local. Com os estande inicial e final calculou-se a porcentagem de plantas sobreviventes. A altura final de plantas foi avaliada pela mensuração de 10 plantas consecutivas na linha central de cada parcela, e os valores expressos em média por parcela.

As determinações da altura de inserção da primeira vagem (AIPV) foram avaliadas pela contagem em 10 plantas consecutivas na linha central de cada parcela. A altura da primeira vagem foi medida por meio de uma haste de madeira com fita métrica fixada. O número de vagens por planta foi avaliado pela contagem em 10 plantas consecutivas linha central de cada parcela. $\mathrm{O}$ número de grãos por vagem foi calculado obtendo uma amostra de 10 vagens, das 10 plantas colhidas, após debulha manual.
A massa de 100 grãos foi obtida pela pesagem de amostra coletada aleatoriamente dos grãos colhidos das 10 plantas de cada parcela, e corrigido o valor para $13 \%$ de umidade. A avaliação da biomassa seca total da cultura da soja, foi determinada pela coleta de 10 plantas consecutivas de cada parcela, que foram secadas e pesadas, obtendo-se o valor da massa seca por meio do estande final de cada tratamento. Para a produtividade, foram coletadas 10 plantas consecutivas da fileira central de cada parcela que foram trilhadas por meio de máquina estacionária, sendo os valores corrigidos para $13 \%$ de umidade.

Os dados foram submetidos à análise de variância, e quando o valor do teste de $\mathrm{F}$ foi significativo a pelo menos $5 \%$ de probabilidade, realizou-se o teste de Tukey a 5\% de probabilidade para a comparação de médias.

Tabela 2. Equipamentos utilizados na execução do segundo ano agrícola.

Table 2. Equipment used in the implementation of the second agricultural year.

\begin{tabular}{|c|c|c|c|}
\hline Equipamento & Marca & Modelo & Características \\
\hline Trator* & Valtra & BH140 & $\begin{array}{l}\text { Potência de } 102 \mathrm{~kW}(140 \mathrm{cv}) \text {, massa de } 8580 \mathrm{~kg} \text {, pneus } 24.5-32 \mathrm{R} 1 \text { no eixo traseiro e } \\
18,4-26 \mathrm{R} 1 \text { no eixo dianteiro, operação de adubação em pré-semeadura. }\end{array}$ \\
\hline Trator* & Valmet & 118 & $\begin{array}{l}\text { Potência de } 82,2 \mathrm{~kW}(112 \mathrm{cv}) \text {, pneus } 18.4-34 \text { no eixo traseiro e } 14.9-26 \text { no eixo } \\
\text { dianteiro, para execução do manejo de resíduos vegetais. }\end{array}$ \\
\hline Trator* & Massey Fergunson & 660 & $\begin{array}{l}\text { Potência de } 110 \mathrm{~kW}(150 \mathrm{cv}) \text {, pneus } 24.5-32 \text { no eixo traseiro e 1.4-26 no eixo dianteiro, } \\
\text { para a semeadura da soja. }\end{array}$ \\
\hline Trator & Massey Fergunson & 275 & $\begin{array}{l}\text { Potência de } 55,0 \mathrm{~kW}(75 \mathrm{cv}) \text {, pneus } 750-16 \text { no eixo dianteiro e } 12,4-38 \text { no eixo traseiro } \\
\text { para aplicação de defensivos agrícolas. }\end{array}$ \\
\hline Distribuidor & Marchesan & $\begin{array}{c}\text { DCCO } \\
5500 \\
\end{array}$ & $\begin{array}{l}\text { Equipamento de arrasto com } 1.260 \mathrm{~kg} \text { sem carga, pneus de baixa pressão e alta flutuação } \\
\text { operação de adubação em pré-semeadura. }\end{array}$ \\
\hline Triturador & Jumil & 2300 & $\begin{array}{l}\text { Equipamento montado no sistema hidraúlico de três pontos, com rotor horizontal de } 61 \\
\mathrm{~cm} \text {, largura de corte de } 2,3 \mathrm{~m}, 32 \text { pares de facas curvas oscilantes e reversíveis, sistema } \\
\text { de regulagem de altura de corte e massa de } 735 \mathrm{~kg} \text {, manejo de resíduos vegetais. }\end{array}$ \\
\hline Rolo faca & LAMMA & & $\begin{array}{l}\text { Equipamento de arrasto com } 13 \text { facas dispostas na periferia, largura de corte de } 2,1 \mathrm{~m} \mathrm{e} \\
\text { massa com lastro de } 720 \mathrm{~kg} \text {, manejo dos resíduos vegetais. }\end{array}$ \\
\hline Roçadora & Avaré & & Equipamento de arrasto, com duas facas oscilantes com largura de corte de $1,6 \mathrm{~m}$. \\
\hline $\begin{array}{l}\text { Semeadora- } \\
\text { adubadora }\end{array}$ & Marchesan & $\begin{array}{c}\text { COP } \\
\text { Suprema } \\
\end{array}$ & $\begin{array}{l}\text { Sete linhas para semeadura, espaçadas de } 0,45 \mathrm{~m} \text {, com haste sulcadora com ângulo de } \\
\text { ataque de } 20^{\circ} \text {, disco de corte de } 45,7 \mathrm{~cm} \text {, disco duplo de } 40,6 \mathrm{~cm} \text {, massa de } 3.070 \mathrm{~kg} \text {. }\end{array}$ \\
\hline Pulverizador & Jacto & $\begin{array}{l}\text { Condor } \\
\text { M12/75 }\end{array}$ & $\begin{array}{l}\text { Tanque de } 600 \mathrm{~L} \text {, massa de } 255 \mathrm{~kg}, 24 \text { bicos tipo leque (XR Teejet }-110.02 \mathrm{VS} \text { para } \\
\text { herbicida e } 110.04 \text { para inseticida) espaçados de } 50 \mathrm{~cm} \text { e largura útil de } 12 \mathrm{~m} \text {, operação } \\
\text { de tratamento fitossanitário. }\end{array}$ \\
\hline
\end{tabular}

\section{RESULTADOS}

A porcentagem de cobertura do solo antes da semeadura (Tabela 3) foi significativa no teste de F para os sistemas de manejo, mas após o teste de médias não ocorreu diferença significativa entre os tratamentos.

A porcentagem de cobertura do solo, com palha aos 30 dias após a semeadura, não ocorreu diferença entre os fatores, mas a cobertura com soja sofreu efeito conjunto dos fatores sistemas de adubação e manejo (Tabela 4).

Analisando os manejos em função do sistema de adubação para a cobertura vegetal com soja, verifica-se que não houve diferença para aplicação de adubo na semeadura (Tabela 4). Mas na adubação em pré-semeadura, observou-se que o rolofaca proporcionou a maior cobertura do solo com soja e a menor com a roçadora. Considerando os manejos individualmente, verificando-se maior eficiência para o rolofaca com adubo em pré-semeadura, já a roçadora foi melhor com adubação na semeadura.

A massa seca no solo antes do manejo e depois da semeadura, assim como as suas interações, não apresentaram diferença significativa (Tabela 5).
No pós-manejo, a massa seca no solo, diferiu para os sistemas de adubação, e para a ação conjunta dos sistemas de adubação e dos manejos (Tabela 5). Desta forma, analisando os sistemas de adubação para a massa seca no solo pós-manejo (Tabela 6), verifica-se que os manejos não diferiram para os sistemas com adubação. Entretanto, ao analisar individualmente os manejos, verifica-se que o manejo com triturador de palhas obteve a menor massa seca no solo, no sistema de adubação na semeadura.

O estande inicial e final das plantas de soja (Tabela 7) não diferiu estatisticamente para os fatores adubação e manejo, como também a sua interação.

A altura de plantas não variou nos sistemas de adubação, manejos e na sua interação (Tabela 7). Já a altura de inserção da primeira vagem obteve diferença significativa para os sistemas de manejo, sendo a maior AIPV com o rolo-faca e a menor para a roçadora.

A porcentagem de plantas sobreviventes não variou em função dos manejos e da adubação, mas ocorreu interação dos fatores (Tabela 8). Observando-se os manejos em cada sistema de adubação, verifica-se que na pré-semeadura não houve diferença entre os manejos, mas no sistema de adubação na 
semeadura o menor número de plantas sobreviventes ocorreu no manejo com triturador de palhas.

Tabela 3. Porcentagem de cobertura do solo com palha antes da semeadura (CI), cobertura do solo com palha depois de 30 dias da semeadura (CP) e com soja (CS) em função do sistema de adubação e manejo dos resíduos vegetais.

Table 3. Percentage of soil cover with straw before sowing (CI), soil cover with straw after 30 days of sowing $(\mathrm{CP})$ and with soybean $(\mathrm{CS})$ as a function of the system of fertilization and management of plant residues.

\begin{tabular}{lccc}
\hline \multirow{2}{*}{ Fatores } & \multicolumn{3}{c}{ Cobertura do solo (\%) } \\
\cline { 2 - 4 } & CI & CP & CS \\
\hline Adubação (A) & \multicolumn{4}{c}{} \\
\hline Pré-semeadura & $47,4 \mathrm{~A}$ & $38,4 \mathrm{~A}$ & $34,9 \mathrm{~A}$ \\
Na semeadura & $48,9 \mathrm{~A}$ & $41,9 \mathrm{~A}$ & $34,0 \mathrm{~A}$ \\
\hline Manejo (M) & & & \\
\hline Rolo-faca & $51,2 \mathrm{~A}$ & $43,2 \mathrm{~A}$ & $37,2 \mathrm{~A}$ \\
Triturador & $42,7 \mathrm{~A}$ & $36,9 \mathrm{~A}$ & $35,0 \mathrm{~A}$ \\
Roçadora & $50,5 \mathrm{~A}$ & $40,4 \mathrm{~A}$ & $31,1 \mathrm{~A}$ \\
\hline Teste F & & & \\
\hline A & $0,2^{\mathrm{ns}}$ & $0,9^{\mathrm{ns}}$ & $0,2^{\mathrm{ns}}$ \\
M & $3,8^{*}$ & $1,0^{\mathrm{ns}}$ & $2,6^{\mathrm{ns}}$ \\
A x M & $0,1^{\mathrm{ns}}$ & $0,2^{\mathrm{ns}}$ & $6,9^{* *}$ \\
\hline CV & 15,8 & 21,6 & 21,1 \\
\hline
\end{tabular}

Médias seguidas de mesma letra na coluna não diferem pelo Teste de Tukey. ns: não significativo $(\mathrm{P}>0,05)$; *: significativo $(\mathrm{P} \leq 0,05)$; **: significativo $(\mathrm{P} \leq 0,01)$. CV: coeficiente de variação $(\%)$

Tabela 4. Desdobramento da interação adubação (A) e manejo (M), para porcentagem de cobertura do solo por soja (CS) em présemeadura e na semeadura.

Table 4. Fertilization interaction (A) and management (M), for percentage of soil cover by soybean (CS) in pre-sowing and sowing.

\begin{tabular}{lcc}
\multirow{2}{*}{ Manejo } & \multicolumn{2}{c}{ Adubação } \\
\cline { 2 - 3 } & Pré-semeadura & Na semeadura \\
\hline Rolo-faca & $43,0 \mathrm{Aa}$ & $31,5 \mathrm{Ab}$ \\
Triturador & $35,0 \mathrm{ABa}$ & $35,0 \mathrm{Aa}$ \\
Roçadora & $26,7 \mathrm{Bb}$ & $35,5 \mathrm{Aa}$ \\
\hline
\end{tabular}

Médias seguidas de mesma letra maiúscula na coluna e minúscula na linha não diferem entre si pelo teste de Tukey a 5\% de probabilidade.

Tabela 5. Atributos de massa seca no solo antes do manejo, após o manejo e depois da semeadura em função do sistema de adubação e manejo dos resíduos vegetais.

Table 5. Attributes of dry mass in the soil before the management, after the management and after sowing in function of the system of fertilization and management of the vegetal residues.

\begin{tabular}{|c|c|c|c|}
\hline \multirow[b]{2}{*}{ Fatores } & \multicolumn{3}{|c|}{ Massa seca no solo $\left(\mathrm{Mg} \mathrm{ha}^{-1}\right)$} \\
\hline & $\begin{array}{c}\text { Antes do } \\
\text { manejo }\end{array}$ & Pós-manejo & $\begin{array}{l}\text { Depois da } \\
\text { semeadura }\end{array}$ \\
\hline \multicolumn{4}{|l|}{ Adubação } \\
\hline Pré-semeadura & $10,4 \mathrm{~A}$ & $10,9 \mathrm{~A}$ & $8,1 \mathrm{~A}$ \\
\hline Na semeadura & $9,5 \mathrm{~A}$ & $8,5 \mathrm{~B}$ & $7,7 \mathrm{~A}$ \\
\hline \multicolumn{4}{|l|}{ Manejo } \\
\hline Rolo-faca & $9,6 \mathrm{~A}$ & $9,3 \mathrm{~A}$ & $8,1 \mathrm{~A}$ \\
\hline Triturador & $9,9 \mathrm{~A}$ & $10,2 \mathrm{~A}$ & $6,8 \mathrm{~A}$ \\
\hline Roçadora & $10,5 \mathrm{~A}$ & $9,7 \mathrm{~A}$ & $9,0 \mathrm{~A}$ \\
\hline \multicolumn{4}{|l|}{ Teste F } \\
\hline Adubação (A) & $0,7^{\mathrm{ns}}$ & $10,8 * *$ & $0,1^{\mathrm{ns}}$ \\
\hline Manejo (M) & $0,2 \mathrm{~ns}$ & $0,5^{\mathrm{ns}}$ & $1,7^{\mathrm{ns}}$ \\
\hline $\mathrm{A} \times \mathrm{M}$ & $1,5^{\mathrm{ns}}$ & $3,6 *$ & $0,2^{\mathrm{ns}}$ \\
\hline $\mathrm{CV}$ & 23,9 & 24,2 & 33,2 \\
\hline
\end{tabular}

Médias seguidas de mesma letra na coluna não diferem pelo Teste de Tukey. ns: não significativo $(\mathrm{P}>0,05)$; *: significativo $(\mathrm{P} \leq 0,05)$; **: significativo $(\mathrm{P} \leq 0,01)$. CV: coeficiente de variação $(\%)$
Tabela 6. Desdobramento da interação adubação (A) e manejo (M), para massa seca no solo $\left(\mathrm{Mg} \mathrm{ha}^{-1}\right)$ para o pós-manejo em présemeadura e na semeadura.

Table 6. Interaction fertilization (A) and management (M), for dry mass in the soil $\left(\mathrm{Mg} \mathrm{ha}^{-1}\right)$ for post-management in before sowing and sowing.

\begin{tabular}{lcc}
\hline & \multicolumn{2}{c}{ Adubação } \\
\cline { 2 - 3 } Manejo & Pré-semeadura & Na semeadura \\
\hline Rolo-faca & $10,7 \mathrm{Aa}$ & $7,9 \mathrm{Aa}$ \\
Triturador & $12,6 \mathrm{Aa}$ & $7,8 \mathrm{Ab}$ \\
Roçadora & $9,6 \mathrm{Aa}$ & $9,8 \mathrm{Aa}$ \\
\hline
\end{tabular}

Médias seguidas de mesma letra maiúscula na coluna e minúscula na linha não diferem entre si pelo teste de Tukey a $5 \%$ de probabilidade.

Tabela 7. Estande inicial (EI $=1000$ plantas), estande final $(E F=1000$ plantas), porcentagem de plantas sobreviventes (PS), altura de plantas (H) e altura de inserção de primeira vagem (AIPV) para as plantas de soja em função do sistema de adubação e manejo dos resíduos vegetais.

Table 7. Initial stand $(E I=1000$ plants $)$, final stand $(E F=1000$ plants), percentage of surviving plants (PS), plant height (H) and first pod insertion height (AIPV) for soybean plants as a function of system of fertilization and management of plant residues.

\begin{tabular}{lccccc}
\hline \multirow{2}{*}{ Fatores } & \multicolumn{5}{c}{ Componentes morfológicos } \\
\cline { 2 - 6 } & EI & EF & $\begin{array}{c}\text { PS } \\
(\%)\end{array}$ & $\begin{array}{c}\mathrm{H} \\
(\mathrm{cm})\end{array}$ & $\begin{array}{c}\text { AIPV } \\
(\mathrm{cm})\end{array}$ \\
\hline Adubação (A) & & & & \\
\hline Pré-semeadura & $326,8 \mathrm{~A}$ & $322,2 \mathrm{~A}$ & $80,2 \mathrm{~A}$ & $67,3 \mathrm{~A}$ & $13,0 \mathrm{~A}$ \\
Na semeadura & $273,1 \mathrm{~A}$ & $277,7 \mathrm{~A}$ & $82,9 \mathrm{~A}$ & $71,4 \mathrm{~A}$ & $11,9 \mathrm{~A}$ \\
\hline Manejo (M) & \multicolumn{5}{c}{} \\
\hline Rolo-faca & $301,4 \mathrm{~A}$ & $301,3 \mathrm{~A}$ & $85,5 \mathrm{~A}$ & $71,2 \mathrm{~A}$ & $14,5 \mathrm{~A}$ \\
Triturador & $311,1 \mathrm{~A}$ & $311,1 \mathrm{~A}$ & $80,8 \mathrm{~A}$ & $68,0 \mathrm{~A}$ & $12,2 \mathrm{AB}$ \\
Roçadora & $287,5 \mathrm{~A}$ & $287,4 \mathrm{~A}$ & $78,4 \mathrm{~A}$ & $69,0 \mathrm{~A}$ & $10,6 \mathrm{~B}$ \\
\hline Teste F & \multicolumn{5}{c}{} \\
\hline A & $4,1^{\mathrm{ns}}$ & $2,3^{\mathrm{ns}}$ & $0,6^{\mathrm{ns}}$ & $2,1^{\mathrm{ns}}$ & $1,2^{\mathrm{nn}}$ \\
M & $0,3^{\mathrm{ns}}$ & $0,2^{\mathrm{ns}}$ & $1,4^{\mathrm{ns}}$ & $0,4^{\mathrm{ns}}$ & $5,1^{*}$ \\
A x M & $0,3^{\mathrm{ns}}$ & $0,5^{\mathrm{ns}}$ & $6,1^{*}$ & $1,8^{\mathrm{ns}}$ & $2,7^{\mathrm{ns}}$ \\
\hline CV & 23,2 & 23,7 & 13,8 & 9,1 & 24,9 \\
\hline Médias seguidas de mesma letra na coluna não diferem pelo Teste de Tukey.
\end{tabular}

Médias seguidas de mesma letra na coluna não diferem pelo Teste de Tukey. ns: não significativo $(\mathrm{P}>0,05)$; *: significativo $(\mathrm{P} \leq 0,05)$; **: significativo $(\mathrm{P} \leq 0,01)$. CV: coeficiente de variação (\%).

Tabela 8. Desdobramento da interação adubação (A) e manejo (M), para porcentagem de plantas sobreviventes em pré-semeadura e semeadura.

Table 8. Interaction fertilization (A) and management (M), for percentage of surviving plants in pre-sowing and sowing.

\begin{tabular}{lcc}
\hline \multirow{2}{*}{ Manejo } & \multicolumn{2}{c}{ Adubação } \\
\cline { 2 - 3 } & Pré-semeadura & Na semeadura \\
\hline Rolo-faca & $85,9 \mathrm{Aa}$ & $85,2 \mathrm{ABa}$ \\
Triturador & $84,2 \mathrm{Aa}$ & $72,5 \mathrm{Ba}$ \\
Roçadora & $71,4 \mathrm{Ab}$ & $90,4 \mathrm{Aa}$ \\
\hline
\end{tabular}

Médias seguidas de mesma letra maiúscula na coluna e minúscula na linha não diferem entre si pelo teste de Tukey a $5 \%$ de probabilidade.

Ao comparar os manejos individualmente (Tabela 8), verificou-se diferença apenas para a porcentagem de plantas sobreviventes no manejo com roçadora, sendo menor no sistema de adubação em pré-semeadura, que está associada a menor cobertura do solo com soja, devido a menor população na área.

A massa de 100 grãos, os grãos por vagem, a massa das plantas de soja, e a produtividade não foram significativos em função dos tratamentos, sistemas de adubação e manejo da palhada, bem como suas interações (Tabela 9).

A produtividade foi a variável que apresentou maior coeficiente de variação $(33,8 \%)$. E pode ter afetado os resultados, uma vez que no fator manejo ocorreu uma 
diferença de $1,9 \mathrm{Mg} \mathrm{ha} \mathrm{h}^{-1}$ entre os tratamentos, o que corresponde a mais de 31 sacas de soja a mais por hectare com o rolo-faca. A massa das plantas de soja (Tabela 9) representa o residual que ficará sobre o solo após a colheita e assim, quanto maior sua quantidade melhor será a cobertura.
Observou-se que o número de vagens por planta (Tabela 9) foi maior nos sistemas de adubação na semeadura, indicando o melhor aproveitamento do adubo pelas plantas de soja. Com relação aos manejos, observou-se que o manejo com rolo-faca obteve o maior número de vagens por planta, e o menor foi o triturador.

Tabela 9. Massa de 100 grãos (M100), número de vagens por planta (VP), número de grãos por vagem (GV), massa seca da soja (MS) e produtividade da soja $(\mathrm{P})$ em função do sistema de adubação e manejo dos resíduos vegetais.

Table 9. 100 grains weight (M100), number of pods per plant (PV), number of grains per pod (GV), soybean mass (MS) and soybean yield (P) as a function of the system of fertilization and management of plant residues.

\begin{tabular}{|c|c|c|c|c|c|}
\hline \multirow{2}{*}{ Fatores } & \multicolumn{5}{|c|}{ Componentes de colheita } \\
\hline & M100 (g) & VP & GV & $\operatorname{MS}\left(\mathrm{Mg} \mathrm{ha}^{-1}\right)$ & $\mathrm{P}\left(\mathrm{Mg} \mathrm{ha}^{-1}\right)$ \\
\hline \multicolumn{6}{|l|}{ Adubação (A) } \\
\hline Pré-semeadura & $15,4 \mathrm{~A}$ & $52,4 \mathrm{~B}$ & $2,2 \mathrm{~A}$ & $4,4 \mathrm{~A}$ & $4,9 \mathrm{~A}$ \\
\hline Na semeadura & $15,4 \mathrm{~A}$ & $61,6 \mathrm{~A}$ & $2,3 \mathrm{~A}$ & $4,5 \mathrm{~A}$ & $5,5 \mathrm{~A}$ \\
\hline \multicolumn{6}{|l|}{ Manejo (M) } \\
\hline Rolo-faca & $15,5 \mathrm{~A}$ & $64,4 \mathrm{~A}$ & $2,3 \mathrm{~A}$ & $5,1 \mathrm{~A}$ & $6,3 \mathrm{~A}$ \\
\hline Triturador & $14,9 \mathrm{~A}$ & $49,3 \mathrm{~B}$ & $2,3 \mathrm{~A}$ & $3,9 \mathrm{~A}$ & $5,1 \mathrm{~A}$ \\
\hline Roçadora & $15,9 \mathrm{~A}$ & $57,4 \mathrm{AB}$ & $2,1 \mathrm{~A}$ & $4,3 \mathrm{~A}$ & $4,4 \mathrm{~A}$ \\
\hline \multicolumn{6}{|l|}{ Teste F } \\
\hline A & $0,1^{\mathrm{ns}}$ & $7,5^{*}$ & $0,1^{\mathrm{ns}}$ & $0,1^{\mathrm{ns}}$ & $0,7^{\mathrm{ns}}$ \\
\hline M & $1,1^{\mathrm{ns}}$ & $6,8^{* *}$ & $2,0^{\mathrm{ns}}$ & $1,3^{\mathrm{ns}}$ & $2,7^{\mathrm{ns}}$ \\
\hline$A \times M$ & $0,3^{\mathrm{ns}}$ & $3,0^{\mathrm{ns}}$ & $0,2^{\mathrm{ns}}$ & $1,2 \mathrm{~ns}$ & $0,7 \mathrm{~ns}$ \\
\hline $\mathrm{CV}$ & 7,9 & 21,5 & 12,6 & 33,6 & 33,8 \\
\hline
\end{tabular}

Médias seguidas de mesma letra na coluna não diferem pelo Teste de Tukey. ${ }^{\text {ns. }}$ não significativo $(\mathrm{P}>0,05)$; *: significativo $(\mathrm{P} \leq 0,05)$; ${ }^{* *}$ : significativo $(\mathrm{P} \leq 0,01)$. CV: coeficiente de variação $(\%)$.

\section{DISCUSSÃO}

A porcentagem de cobertura vegetal do solo após a semeadura em relação à inicial diminui e conforme Cortez (2007) pode ocorrer diminuição de $40 \%$, devido a ação dos mecanismos sulcadores no solo, revolvendo-o e mantendo o material nas entre fileiras da cultura.

Pode-se explicar esses resultados, baseado na ação destes equipamentos sobre os resíduos vegetais e plantas espontâneas na área, uma vez que o rolo-faca amassa a cultura matando a planta, já a roçadora apenas faz uma poda nas plantas mantendo-as vivas, e consequentemente com capacidade para absorção de nutrientes do solo. Neste caso, pode justificar a menor cobertura da área com soja na roçadora em présemeadura, por absorção de parte dos nutrientes por plantas espontâneas na área, deixando menor disponibilidade para a soja. Teixeira et al. (2012) afirmam que plantas com sistema radicular mais superficial, podem se beneficiar de nutrientes aportados ao solo e com isto, apresentarem maior quantidade de biomassa.

Entretanto, Silva et al. (2012) relataram que o uso do rolofaca tem se mostrado como uma alternativa nas estratégias para adequado manejo na sucessão das culturas arroz-soja, por promover a incorporação da palha de arroz modificando a qualidade do solo. Borges et al. (2014) ao realizarem manejo de plantas de cobertura do solo utilizando roçagem mecânica e dessecação com herbicida, verificaram cobertura do solo superior a $80 \%$ até o florescimento da soja.

Apesar da falta de significância no manejo da palhada neste trabalho, verificou-se, no entanto, efeito no desenvolvimento da soja, que proporcionou maior cobertura vegetal sobre o solo. Para Rossi et al. (2013) deve-se em decorrência das características qualitativas dos resíduos vegetais, associados às condições edafoclimáticas.

O comportamento do triturador de palha no sistema de adubação na semeadura pode ser atribuído à grande quantidade de biomassa acumulada na área, que favoreceu com maiores teores de umidade do solo e a atividade microbiana, além do efeito da relação $\mathrm{C} / \mathrm{N}$ das plantas de cobertura do solo (ROSSI et al., 2013). A maior biomassa seca no solo em pré-semeadura pode também ser atribuída a adubação antecipada, que proporcionou maior nível de nutrientes as plantas espontâneas na área.

O estande de plantas, de acordo com Trogello et al. (2013), com plantas distribuídas de forma não homogênea na área, pode-se alcançar produtividades similares em virtude das boas condições edáficas e de manejo aos quais a lavoura foi submetida e a manutenção do estande. Normalmente, para a cultura da soja, o estande de plantas pouco interfere na produtividade da cultura, uma vez que a planta de soja pode compensar falhas da semeadura pela emissão de novos ramos.

A não significância na altura de plantas pode ser atribuída conforme Garcia et al. (2014) ao avaliarem a decomposição da palhada de Urochloa e Panicum no desempenho agronômico da soja em sucessão no Cerrado, devido as taxas de decomposição e mineralização das palhadas terem sido semelhantes e o solo apresenta fertilidade razoável e histórico de oito a nove anos em sistema plantio direto.

Como a altura de inserção da primeira vagem é um fator importante na fase de colheita, Leite et al (2015) afirmam que plantas mais altas na floração e consequentemente, com maior altura na maturidade, apresentam também maior altura de inserção da primeira vagem, sendo a altura satisfatória em torno de $15 \mathrm{~cm}$. Porém, Santos et al. (2013) não verificaram diferença na altura de plantas e altura de inserção das primeiras vagens de soja quando avaliaram o efeito dos sistemas de produção com ILP (Integração-Lavoura-Pecuária) na produtividade de grãos e características agronômicas de soja.

Quanto a porcentagem de plantas sobreviventes, Trogello et al. (2013) afirmam que o maior fracionamento da palhada permite uma penetração melhor de luz, homogeneidade maior de temperatura e umidade ao longo da área e por conseguinte, melhores condições de sobrevivência da cultura. Isto pode 
estar relacionado com a menor quantidade de palha sobre o solo, pois solo descoberto apresenta menor armazenamento de água, seca mais rápido e consequentemente tem piores condições para o desenvolvimento inicial das plântulas.

A não significância da variável número de grãos também foi verificada por Santos et al. (2014) quando avaliaram o efeito de sistemas de rotação de culturas (sistemas 1 trigo/soja; sistema 2 - trigo/soja e ervilhaca/milho ou sorgo e sistema 3 - trigo/soja, aveia branca/soja e ervilhaca/milho ou sorgo) sobre a produtividade de grãos e características agronômicas da soja.

A produtividade foi a variável que se verificou maior coeficiente de variação; entretanto, Leite et al. (2015) afirmam que o alto valor para coeficiente de variação desta característica é aceitável nas condições em que foi avaliado por ser quantitativa e bem influenciada pelo ambiente. A produtividade da cultura da soja depende de vários fatores e de acordo com Meoti et al. (2012) os componentes de produção apresentara ajustes entre as cultivares, para compensar os efeitos da época de semeadura. Cortez et al. (2011) não verificaram alterações na produtividade, quando utilizaram densidade populacional de 15 a 20 plantas por metro.

A massa residual, quanto maior a sua quantidade melhor será a cobertura do solo, desta forma, conforme Rossi et al. (2013) as plantas com grande quantidade de massa residual constituem uma alternativa para proteção do solo e principalmente quando estas plantas geram palhada que possuem maiores tempos de meia-vida.

O número de vagens por planta segundo Busanello et al. (2013) obteve ajuste linear, ou seja, com o aumento da densidade da população pode-se verificar diminuição da produção absoluta por planta. Assim sendo, apesar da redução das vagens por planta e com o maior número de plantas por metro quadrado tem-se um maior número de vagens por área, potencializando a produtividade.

\section{CONCLUSÕES}

Os sistemas de manejo, individualmente, influenciaram as variáveis estande, altura de inserção da primeira vagem e número de vagens por planta.

A interação sistema de manejo de palhada e adubação, seja na semeadura ou pré-semeadura, não influenciaram a produtividade da soja.

\section{AGRADECIMENTOS}

A CAPES pela concessão de bolsa de doutorado do primeiro autor.

\section{REFERÊNCIAS}

BEUTLER, N. A.; MUNARETO, J. D.; GRECO, A. M. F.; POZZEBON, B. C.; GALON, L.; GUIMARÃES, S.; BURG, G.; SCHMIDT, M. R.; DEAR, E. A.; GIACOMELI, R.; ALVES, G. S. Manejo do solo, palha residual e produtividade de arroz irrigado por inundação. Semina: Ciências Agrárias, Londrina, v. 35, n. 3, p. 1153-1162, 2014. DOI: http://dx.doi.org/10.5433/16790359.2014v35n3p1153

BORGES, W. L. B.; FREITAS, R. S.; MATEUS, G. P.; SÁ, M. E.; ALVES, M. C. Supressão de plantas daninhas utilizando plantas de cobertura do solo. Planta Daninha, Viçosa, v. 32, n. 4, p. 755-763, 2014. DOI: http://dx.doi.org/10.1590/S0100-83582014000400010
BUSANELLO, C.; BATTISTI, R.; SOMAVILLA, L.; MENEGOL, D. R. Caracteres agronômicos da cultura da soja submetida a diferentes densidades populacionais na região norte do Rio Grande do Sul. Enciclopédia Biosfera, Goiânia, v. 9, n. 17, p. 509-517, 2013.

CHIODEROLI, C. A.; MELLO, L. M. M.; GRIGOLLI, P. J.; FURLANI, C. E. A.; SILVA, J. O. R.; CESARIN, A. L. Atributos físicos do solo e produtividade de soja em sistema de consórcio milho e braquiária. Revista Brasileira de Engenharia Agrícola e Ambiental, Campina Grande, v. 16, n. 1, p. 37-43, 2012. DOI: http://dx.doi.org/10.1590/S1415-43662012000100005

CORTEZ, J. W. Densidade de semeadura da soja e profundidade de deposição do adubo no sistema plantio direto. 2007. 87f. Tese (Doutorado em Agronomia - Produção Vegetal) -Universidade Estadual Paulista, Faculdade de Ciências Agrárias e Veterinárias FCAV, Jaboticabal, 2007.

CORTEZ, J. W.; FURLANI, C. E. A.; SILVA, R. P.; ROMÁN, R. A. A. Características agronómicas de la soya em función de las densidades de siembra e profundidade de deposición de abono. Revista Ceres, Viçosa, v. 58, n. 1, p. 62-68, 2011. DOI: http://dx.doi.org/10.1590/S0034737X2011000100010

DOMIT, L. A.; OKUMURA, R. S.; BARBOSA, G. M. C.; HIGASHIBARA L. R.; DALBOSCO, M.; MARIANO, D. C.; ZORZENONI, T. O.; GUIMARÃES, M. F. Tempo de adoção do sistema plantio direto e a relação com atributos do solo. Agrarian, v. 7, n. 26, p. 560-569, 2014.

EMBRAPA_EMPRESA BRASILEIRA DE PESQUISA AGROPECUÁRIA. Sistema brasileiro de classificação de solos. 3.ed. Brasília, 2013. 353 p.

GARCIA, C. M. P.; ANDREOTTI, M.; TEIXEIRA FILHO, M. C. M.; LOPES, K. S. M.; BUZETTI, S. Decomposição da palhada de forrageiras em função da adubação nitrogenada após o consórcio com milho e produtividade da soja em sucessão. Bragantia, Campinas, v. 73, n. 2, p. 143-152, 2014.2 DOI: http://dx.doi.org/10.1590/brag.2014.016

GUARESCHI, R. F.; GAZOLLA, P. R.; PERIN, A.; SANTINI, J. M. K. Adubação antecipada na cultura da soja com superfosfato triplo e cloreto de potássio revestidos por polímeros. Ciênc. agrotec., Lavras, v. 35, n. $4, \quad$ p. 643-648, 2011. DOI: http://dx.doi.org/10.1590/S1413-70542011000400001

KRUTZMANN, A.; CECATO, V.; SILVA, P. A.; TORMENA, C. A.; IWAMOTO, B. S.; MARTINS, E. M. Palhadas de gramíneas tropicais e rendimento da soja nos sistemas de integração lavoura-pecuária. Bioscence Journal, Uberlândia, v. 29, n. 4, p. 842-851, 2013.

LAFLEN, J. M.; AMEMIYA, M.; HINTZ, E. A. Measuring crop residue cover. Journal of Soil and Water Conservation, Ankeny, v. 36, n. 6, p. 341-343, 1981.

LEITE, W. S.; PAVAN, B. E.; MATOS FILHO, C. H. A.; FEITOSA, F. S.; OLIVEIRA, C. B. Estimativas de parâmetros genéticos e correlações entre caracteres agronômicos em genótipos de soja. Nativa, Sinop, v. 3, n. 4, p. 241-245, 2015. DOI: http://dx.doi.org/10.14583/2318-7670.v03n04a03

MEOTI, G. V.; BENIN, G.; SILVA, R. R.; BECHE, E.; MUNARO, L. B. Época de semeadura e desempenho agronômico de cultivares de soja. Pesquisa Agropecuária Brasileira, v. 47, n. 1, p. 14-21, 2012. 
ORMOND, A. T. S. Sistemas de semeadura e manejo do solo no desenvolvimento da cultura da soja. 2013. 74f. Dissertação (Mestrado em Engenharia Agrícola) Universidade Federal do Mato Grosso, Instituto de Ciências Agrárias e Tecnológicas, Rondonópolis, 2013.

RAIJ, B. V.; SILVA, N. M.; BATAGLIA, O. C.; GUAGGIO, J. A.; HIROGE, R.; CANTARELLA, H.; BELLINAZZI JÚNIOR, R.; DECHEN, A. R.; TRANI, P. E. Recomendações de adubação e calagem para o Estado de São Paulo. Campinas: IAC, 1985. 107 p.

ROSSI, C. Q.; PEREIRA, M. G.; GIACOMO, S. G.; BETTA, M.; POLIDORO, J. C. Decomposição e liberação de nutrientes da palhada de braquiária, sorgo e soja em áreas de plantio direto no cerrado goiano. Semina: Ciências Agrárias, Londrina, v. 34, n. 4, p. 1523-1534, 2013. DOI: 0359.2013v34n4p1523

SANTOS, H. P.; FONTANELI, R. S.; PIRES, J.; LAMPERT, E. A.; VARGAS, A. M.; VERDI, A. C. Rendimento de grãos e características agronômicas de soja em função de sistemas de rotação de culturas. Bragantia, Campinas, v. 73, n. 3, p. 263-273, 2014. DOI http://dx.doi.org/10.1590/1678-4499.0136

SANTOS, H. P.; FONTANELLI, R. S.; SPERA, S. T.; MALDANER, G. L. Rendimento de grãos de soja em diferentes sistemas de produção integração lavourapecuária. Revista Brasileira de Ciências Agrárias (Agrária), Recife, v. 8, n. 1, p. 49-56, 2013. DOI: http://dx.doi.org/10.5039/agraria.v8i1a2077
SILVA, A. F.; LAZARINI, E. Doses e épocas de aplicação de potássio na cultura da soja em sucessão a plantas de cobertura. Semina: Ciências Agrárias, Londrina, v. 35, n. $1, \quad$ p. 179-192, 2014. DOI: http://dx.doi.org/10.5433/1679-0359.2014v35n1p179

SILVA, J. J. C.; THEISEN, G.; ANDRES, A.; SILVA, J. L. S.; IDEHARA, S. J. Avaliação do uso de rolo-faca no preparo do solo pós-colheita do arroz irrigado em área da planície costeira do RS. Pelotas: Embrapa Clima Temperado, 2012. 28p. (Comunicado Técnico, 349)

TAVARES, L. A. F.; BENEZ, S. H.; SILVA, P. R. A. Características agronômicas e demanda energética de cultivares de soja sob efeito dos sistemas de preparo do solo. Energia na Agricultura, v. 27, n. 4, p. 92-108, 2012.

DOI: http://dx.doi.org/10.17224/EnergAgric.2012v27n4p92108

TEIXEIRA, M. B.; LOSS, A.; PEREIRA, M. G.; PIMENTEL, C. Decomposição e ciclagem de nutrientes dos resíduos de quatro plantas de cobertura do solo. Idésia, Arica, v. 30 , n. $1, \quad$ p. 55-64, 2012. DOI: http://dx.doi.org/10.4067/S0718-34292012000100007

TROGELLO, E.; MODOLO, A. J.; SCARSI, M.; SILVA, C. L.; ADAMI, P. F.; DALLACORT, R. Manejos de cobertura vegetal e velocidades de operação em condições de semeadura e produtividade de milho. Revista Brasileira de Engenharia Agrícola e Ambiental, Campina Grande, v. 17, n. 7, p. 796-802, 2013. DOI: http://dx.doi.org/10.1590/S141543662013000700015 